and $\$ 2.00$ respectively per unit, so that detecting each unit of infected blood would cost $\$ 6.25(\$ 0.50 \div 0 \cdot 8 \%)$ for counterimmunoelectrophoresis, $\$ 45.50$ ( $\$ 1.00 \div$ $2 \cdot 2 \%)$ with reverse passive haemagglutination, and $\$ 28.60(\$ 2.00 \div 7 \%)$ with ELISA. Screening with these three methods would avert giving a potentially infectious transfusion in $1.4 \%, 3.5 \%$, or $10.8 \%$ of recipients, respectively (table). Thus the actual cost per recipient of preventing infection from transfusion of three units would be $\$ 107(3 \times \$ 0.50 \div 1.4 \%)$ for counterimmunoelectrophoresis, $\$ 86(3 \times \$ 1.00 \div 3 \cdot 5 \%)$ for reverse passive haemagglutination, and $\$ 56(3 \times$ $\$ 2.0 \div 10 \cdot 8 \%$ ) for ELISA

\section{Comment}

We previously found that screening donor blood by counterimmunoelectrophoresis reduced the incidence of jaundice after transfusion from $9 \cdot 4 \%$ to $2 \cdot 2 \%$.' This method is unlikely to be so effective now: systematic elimination of carriers with high titres of HBsAg and exclusion of paid donors have probably resulted in an increased proportion of carriers with low titres of antigen among the population of blood donors, who would be detected only by more sensitive screening tests such as reverse passive haemagglutination or ELISA.

Although the cost of reverse passive haemagglutination is twice and of ELISA four times that of counterimmunoelectrophoresis, they confer 2.5 and $7 \cdot 7$ times the benefit, respectively. ELISA averted potential infection most cheaply and counterimmunoelectrophoresis at greatest cost. We therefore recommend that highly sensitive tests such as ELISA, which uses monoclonal antibodies, should be used to screen blood in transfusion centres in developing countries.

We thank Mrs S Christopher, Mrs T Padankatti, Dr A Sudarshanam, and Dr R Pulimood for help and advice. This study was supported by the Epidemiology Resource Centre which is funded by the Ford Foundation, and by the Indian Council of Medical Research, New Delhi.

1 John TJ, Carman RH, Hill PG. Hepatitis B antigen and viral hepatitis B in India. Bull WHO 1974:51:617-9.

2 Ryder RW, Whittle HC, Woijecowsky T, et al. Screening for hepatitis B virus markers is not justified in west African transfusion centres. Lancet 1984;ii:449-52.

3 Shanmugam RV, John TJ, Hill PG, Carman RH. Comparative sensitivity of cross over electrophoresis and complement fixation tests for the detection of Australia antigen. Indiun 7. Med Res 1973:61:521-4.

Accepted $1+$ March 1988

\title{
Treatment of ingrowing toenails by surgeons and chiropodists
}

\section{P A Sykes, R Kerr}

Departments of Surgery and Chiropody, Trafford Hospitals, Manchester P A Sykes, FRCS, consultant surgeon

R Kerr, MCHS, chiropodist

Correspondence to: $\mathrm{MrPA}$ Sykes, Park Hospital, Manchester M31 3SL.
Ingrowing toenails (onychocryptosis) usually affect the hallux and are most common in patients aged 15-40. Surgeons most commonly treat ingrowing toenails by avulsion, ' despite a reported recurrence rate of over $60 \%$. $^{2}$ Chiropodists most commonly use segmental phenolic ablation, a technique that has been well illustrated elsewhere, ${ }^{3}$ although this was offered by only five of 106 consultant surgeons.' Although ingrowing toenails are common, the treatments available have not been critically evaluated.

\section{Patients, methods, and results}

In a preliminary prospective study 140 consecutive patients with 164 ingrowing hallux nails were treated by avulsion of the nail. Recurrence, defined as penetration of the nail fold by the nail, was present in $32 \%$ of patients at follow up after one year and $42 \%$ after three years.

As many different techniques can be used to ablate the nail bed' a second study compared the effectiveness of ablation with a chemical and surgical ablation. One hundred and fifty two patients were prospectively and randomly allocated to receive either total phenolic ablation or total excision of the nail bed with a knife (Zadik's operation). The overall recurrence rate was $14 \%$, with no significant difference between the groups, although one surgeon had only one recurrence after 21 Zadik's operations.

A third prospective study compared the operation most commonly recommended by surgeons (avulsion) with that most commonly recommended by chiropodists (segmental phenolic ablation) and compared the success of segmental phenolic ablation performed by surgeons and chiropodists. Altogether 424 patients attending either surgeons or chiropodists were studied. In all cases the blood supply and skin nutrition of the foot were normal. Patients who presented to the surgeons were randomly allocated to treatment with avulsion $(n=45)$ or segmental phenolic ablation. Those allocated to receive segmental phenolic ablation were added to the patients presenting to chiropodists, and patients from this common pool were randomly allocated to be treated by surgeons $(n=197)$ or chiropodists $(n=182)$. This format was chosen because the chiropodists asked not to perform avulsion as they regarded its results as unsatisfactory. Preliminary results of treatment by avulsion were disappointing so we stopped assigning patients to this treatment. The patients treated by avulsion continued to be followed up. Though patients who did not attend for postoperative checks were contacted by post or telephone, the outcome was not known in 79 cases.

Treatment was regarded as successful if patients remained free of symptoms throughout the 12 months of follow up. The table shows that where outcome was known chiropodists and surgeons achieved an overall success rate of $95 \%$ with segmental phenolic ablation; a $47 \%$ success rate was achieved with avulsion.

Outcome of 424 cases of ingrowing toenails 12 months after treatment. Numbers in parentheses are percentages of those for which outcome was known

\begin{tabular}{|c|c|c|c|}
\hline & Recurrence & Good result & $\begin{array}{c}\text { Result } \\
\text { not } \\
\text { known }\end{array}$ \\
\hline $\begin{array}{l}\text { Avulsion } n-45 \\
\text { Segmental ablation bv chiropodist }\end{array}$ & $20(53)$ & $18(+7)$ & 7 \\
\hline$(n=182)$ & $+(3)$ & $1+1(97)$ & 37 \\
\hline Segmental ablation by surgeon $(n=197)$ & $11(7)$ & $151(93)$ & 35 \\
\hline
\end{tabular}

\section{Comment}

These studies of patients with ingrowing toenails show an unacceptable rate of recurrence after simple avulsion (over $40 \%$ at three years). The incidence of nail regrowth after total phenolic ablation and after Zadik's operation was not significantly different, but the success of Zadik's operation seems to depend on the surgeon. The recurrence rate at 12 months after segmental phenolic ablation was only $5 \%$, chiropodists achieving slightly better results than surgeons.

The rough cost of surgical treatment in our hospital is $£ 68$, compared to $£ 20$ for treatment in our chiropody clinic. If the 10000 new cases of ingrowing toenail seen each year in the United Kingdom were treated by segmental phenolic ablation in chiropody clinics 
$£ 480000$ would be saved. As segmental phenolic ablation results in fewer recurrences savings would be greater as the number of reoperations would fall: we would recommend that patients with a systemic or arterial disease, which might impair healing, should, however, be treated by doctors.

The treatment chosen for ingrowing toenails should have a low recurrence rate and a reasonable cost. ${ }^{+}$If patients were referred to a suitably trained-state registered-chiropodist for segmental phenolic ablation this ideal might be attained.

1 Sykes P'A. Ingrowing toenails: time for critical appraisal? $7 R$ (Coll Surg Edmb $1986: 31: 300-4$.

2 Murray WR, Bedi BS. The surgical management of ingrowing toenails. $B r$. Surg $1975 ; 62: 409 \cdot 12$

3 Wallace A, W'oodside J, Long J. Ingrowing toenails. I'ulse 1986 July 12: 25-32. + Miller SS. Ingrowing toenails. Br.Med 7 1985;291:91-2.

Accepled 2.March 1988
Malvern, Worcestershire WR143BL M C Colquhoun, MRCP, general practitioner

\section{Use of defibrillators by general practitioners}

\author{
M C Colquhoun
}

Roughly $60 \%$ of deaths from myocardial infarction occur outside hospital and are due to ventricular fibrillation occurring shortly after the onset of symptoms. ' All methods of resuscitation administered outside hospital aim at giving a defibrillatory shock with the minimum delay. In Britain many patients summon a general practitioner during the early stages of myocardial infarction, and evidence suggests that around $5 \%$ of such patients experience a cardiac arrest in the presence of a general practitioner, who is therefore ideally situated to attempt resuscitation..$^{23}$

The proceeds of the 1985 London to Brighton cycle ride enabled the British Heart Foundation to donate 78 defibrillators to general practice. This report describes the impact of these defibrillators and investigates the circumstances in which a British general practitioner. might perform defibrillation. Potential hazards and problems were also investigated.

\section{Patients, methods, and results}

Practices were selected to receive Lifepak -5 defibrillators on the basis of a questionnaire circulated to all general practitioners in Britain, taking account of training, size of practice, distance from hospital, and whether the local ambulance service had defibrillators. All recipients were asked to return a questionnaire every time the machine was used, recording basic data about the patient, the circumstances in which cardiac arrest occurred, initial rhythm, and methods used in the resuscitation attempt. The outcome, final diagnosis, technical problems, and injuries were also recorded. Nil returns were also collected.

Twenty five practices ( 99 doctors) recorded use of the defibrillator; 24 practices ( 100 doctors) recorded no use during the year studied. Fifty three attempts at resuscitation were made; $16(30 \%)$ of the patients reached hospital alive, $10(19 \%)$ were eventually discharged. Success was highest when ventricular fibrillation was the initial rhythm: 32 patients, 12 $(37 \%)$ reaching hospital alive and seven $(22 \%)$ were discharged. When asystole was the initial rhythm results were much poorer: 18 patients, one reaching hospital and subsequently being discharged. The estimated time to reach patients in ventricular fibrillation was 4.8 minutes and in asystole nine minutes, suggesting that those in the second group were suffering the terminal asystole that follows ventricular fibrillation.

Nineteen patients suffered arrests in the presence or immediate vicinity of a general practitioner (table); 13 developed ventricular fibrillation and the remainder were converted to ventricular fibrillation and subsequently defibrillated. Initial success $(68 \%)$ and hospital discharge rate $(47 \%)$ were excellent.
Myocardial infarction was responsible for 44 cardiac 등 arrests, but the following conditions were also re- $\bar{\omega}$ corded once: left atrial myxoma, haemorrhage from $\widehat{\Phi}$ lymphoma, cerebrovascular accident, aortic stenosis, myocarditis, multiple injuries, and idiopathic ventricular fibrillation.

Outcome of cardiac arrests occurring in the presence or vicinity of a general practitioner

Resuscitation Survival to Discharged

\begin{tabular}{|c|c|c|c|c|}
\hline \multicolumn{5}{|l|}{ Ventricular } \\
\hline Asystole & 3 & 2 & 1 & 1 \\
\hline $\begin{array}{l}\text { Broad complex } \\
\text { tachycardia (with } \\
\text { no output) }\end{array}$ & 2 & 0 & 2 & 1 \\
\hline $\begin{array}{l}\text { Electromechanical } \\
\text { dissociation } \\
\text { Total }\end{array}$ & $\begin{array}{r}1 \\
19\end{array}$ & $\begin{array}{l}0 \\
6\end{array}$ & ${ }_{13}^{1}(68 \%)$ & $9_{9(47 \%)}^{1}$ \\
\hline
\end{tabular}

\section{Comment}

The 25 defibrillators used in the first year after their provision to general practitioners saved 10 lives. The results confirm that a significant number of patients suffer arrest near a general practitioner, who, if suitably trained and equipped, stands an excellent $\mathbb{D}$ chance of saving their life. Such general practitioners $\underset{\vec{P}}{\vec{F}}$ may play an important part in reducing the mortality of myocardial infarction by reaching patients quickly (preferably before the onset of serious arrhythmias) and educating susceptible patients to summon help immediately after the onset of symptoms.

The long term prognosis for such patients is excellent, ${ }^{4}$ suggesting that defibrillators are a sound and cost $\frac{5}{3}$ effective investment. One can be bought for $£ 1350$.

Conditions other than myocardial infarction occur with sufficient frequency for the general practitioner not to assume automatically that ischaemic heart disease is responsible for all cardiac arrests.

Few technical problems and no serious injuries occurred during resuscitation, in agreement with the findings of Cummings and Eisenberg, who emphasised $N$ the safety of cardiopulmonary resuscitation, a point $N$ that needs emphasis in view of the increasing number of attempts at resuscitation being made in the community.

I thank all doctors who contributed to the survey and all $\stackrel{\mathcal{?}}{+}$ staff of the British Heart Foundation, Professor D G Julian 7 for his invaluable advice, and Hazel Davies of Syntex Cardiovascular for secretarial help.

\footnotetext{
1 Armstrong A, Duncan B, Oliver MF, et al. Natural history of acute coronary attacks. A community study. Br Heurt 7 1972;34:67-80.

2 Rawlins DC:. Study of the management of suspected cardiac infartion by British immediate care doctors. Br Med 7 1981;282:1677-9

3 P'ai GR, Haites NE, Rawles JM. One thousand heart attacks in Grampian: the place of cardiopulmonary resuscitation in general practice. Br Med $\mathcal{y}$ 1987:294:352-4.

+ Cobb LA. Baum RS, Alvares H III, Schaffer WA. Resuscitation from out of hospital ventricular fibrillation: 4 vears' follow-up. ('irculation 1975;51 supp III $: 223-8$

5 ( Cummins RO), Eisenherg MS (ardiopulmonary resuscitation American style. BrMed 7 1985;291:1401-3.
}

Accepted 6 A pril 1988 